\title{
Cysteine-derived Cross-linker for Anionic UV Curing of Epoxy Resins
}

\author{
Masahiro Furutani, Shinya Sato and Koji Arimitsu* \\ Department of Pure and Applied Chemistry, Tokyo University of Science, \\ 2641 Yamazaki, Noda, Chiba 278-8510, Japan \\ *arimitsu@rs.noda.tus.ac.jp
}

Keywords: cysteine, cross-linker, anionic UV curing, epoxy resin, thiol, amine

\section{Introduction}

Epoxy resins are one of famous thermosetting resins, and they have been used to fabricate many industrial materials such as electronic parts, adhesives and coating films [1]. Network polymers in their cured materials are formed with cross-linkers or hardeners. Alcohols, phenols, carboxylic acids, acid anhydrides, and amines have been examined as hardners [2]. Recently, our group has developed an epoxy resin curing system with a tetrafunctional thiol and photobase generator providing a strong organic base [3]. In this communication, we have focused a unique chemical structure of L-cysteine (Cys) which has thiol and primary amino groups. Both functional groups can be used to form cross-linked networks with epoxy resins, and we examined roles of these functional groups in a UV-triggered anionic curing reaction of an epoxy resin (Scheme 1). Thiol group of Cys-derived cross-linker $\mathbf{1}$ is protected by a photolytic protecting group decomposing via an intramolecular cyclization reaction $[4,5]$. On the other hand, amino group of $\mathbf{1}$ is protected by 9-fluorenylmethyloxycarbonyl (Fmoc) group that is decomposed by basic species [6] Another functional group, carboxyl group, is used for adjustment of solubility of the derivative.

\section{Method}

Cys-derived cross-linker $\mathbf{1}$ was synthesized from Fmoc-Cys(Trt)-OH (an available compound for solid phase peptide synthesis, Trt: trityl) in a $46 \%$ total yield via four reaction steps. Identification was performed by ${ }^{1} \mathrm{H}$ NMR, ${ }^{13} \mathrm{C}$ NMR, FT-IR, and high resolution MS. Decomposition behaviors of $\mathbf{1}$ were investigated in a poly(tetramethylene ether glycol) (PTMG) film with 365 $\mathrm{nm}$ light irradiation or heating at $120^{\circ} \mathrm{C}$ in the presence of 2-methyl-1,5-diaminopentane, monitored by FT-IR. Anionic UV curing of a tetrafunctional epoxy resin (NN) was performed by $365 \mathrm{~nm}$ light irradiation and postbaking at $120^{\circ} \mathrm{C}$ for $30 \mathrm{~min}$. Preliminary adhesion test was performed at room temperature with stainless substrates at a shear speed of $50 \mathrm{~mm} / \mathrm{min}$.

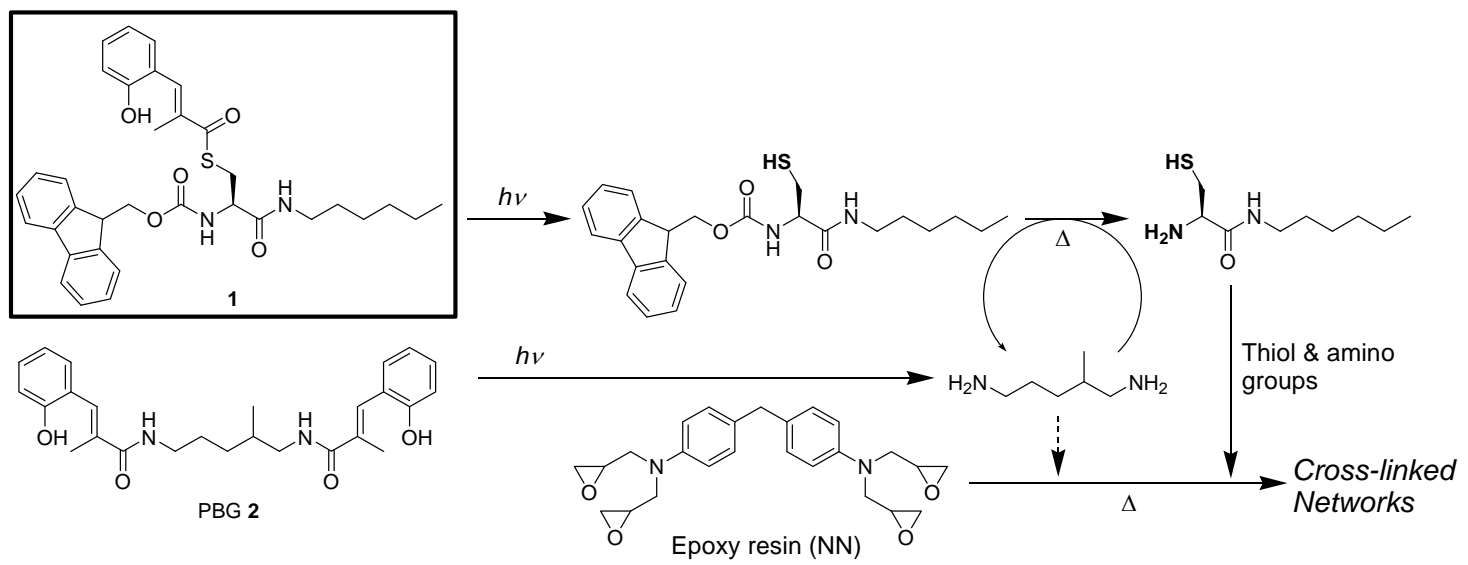

Scheme 1. Anionic UV curing system of a tetrafunctional epoxy resin (NN) containing Cys-derived cross-linker 1 and PBG 2. 

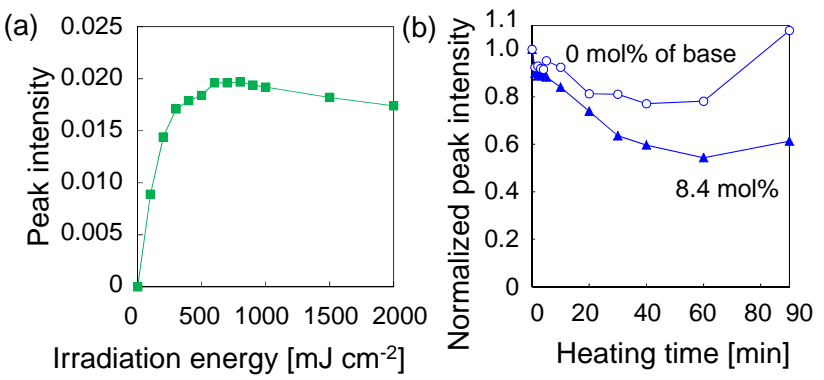

Figure 1. Decomposition behaviors of $\mathbf{1}$, monitored by FT-IR. (a) Generation of a coumarin analogue by-product (1723 $\mathrm{cm}^{-1}$ ) during $365 \mathrm{~nm}$ light irradiation. (b) Consumption of Fmoc groups of $1\left(1658 \mathrm{~cm}^{-1}\right)$ with 0 (circle, open) or $8.4 \mathrm{~mol} \%$ (triangle, close) of diamine during heating at $120^{\circ} \mathrm{C}$.

\section{Results and Discussion}

Cys-derived cross-linker 1 was well dissolved toward common organic solvents such as alcohols, acetone, THF, dichloromethane and ethyl acetate. A PTMG film containing 1 was prepared, and $365 \mathrm{~nm}$ light was irradiated to monitor the intensity of a peak at $1723 \mathrm{~cm}^{-1}$ assigned to carbonyl group of the coumarin analogue by-product (Figure 1a). Increase and saturation of the intensity indicated that the protecting group of thiol group of $\mathbf{1}$ is quantitatively photodecomposed. On the other hand, liberating amino group of $\mathbf{1}$ was confirmed by monitoring peak intensity of the carbonyl group of Fmoc moiety at $1658 \mathrm{~cm}^{-1}$ (Figure 1b). The peak intensity was decreased during heating at $120^{\circ} \mathrm{C}$ in the presence of 8.4 mol\% of diamine (toward $\mathbf{1}$ ), while the intensity did not change after heating for $90 \mathrm{~min}$ without diamine.

An anionic UV curing was then performed with 1, PBG 2 [7] and NN as shown in Scheme 1, to examine the curing ability of $\mathbf{1}$. Hardness of cured-films was evaluated by the pencil-scratch method based on JIS $\mathrm{K} 5400$ [8]. The hardness of pencil is arranged as follows: 6B (softest), 5B, 4B, 3B, 2B, B, HB, F, H, 2H, 3H, 4H, $5 \mathrm{H}, 6 \mathrm{H}, 7 \mathrm{H}, 8 \mathrm{H}, 9 \mathrm{H}$ (hardest). Results are shown in Figure 2. Without UV irradiation, films were not cured, and the hardness value was below 6B. Increasing irradiation energy made the resulting cured films hard, and the maximum value of $2 \mathrm{~B}$ was recorded with 10000 $\mathrm{mJ} \mathrm{cm}$ of irradiation. On the other hand, in the case without PBG 2 (1/NN in the Figure), the value of $6 \mathrm{~B}$ was obtained after $10000 \mathrm{~mJ} \mathrm{~cm}^{-2}$ of irradiation, indicating that amino groups of $\mathbf{1}$ contribute mainly to the curing. Nevertheless, thiol groups of $\mathbf{1}$ also contribute a little, because films were not cured at all in the case without $\mathbf{1}$ (2/NN in the Figure). Finally, a preliminary adhesion test was performed under these conditions $\left(10000 \mathrm{~mJ} \mathrm{~cm}^{-2}\right.$ of

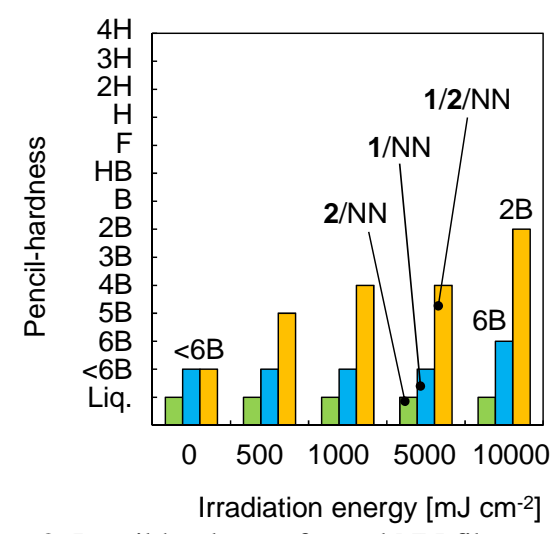

Figure 2. Pencil-hardness of cured NN films containing 11 mol\% of 1 and/or 1.1 mol\% of 2 (toward epoxy groups of $\mathrm{NN}$ ) after $0-10000 \mathrm{~mJ} \mathrm{~cm}^{-2}$ of $365 \mathrm{~nm}$ light irradiation and postbaking at $120^{\circ} \mathrm{C}$ for $30 \mathrm{~min}$.

$365 \mathrm{~nm}$ light irradiation, subsequent heating at $120^{\circ} \mathrm{C}$ for $30 \mathrm{~min}$ ). A clear difference of shear strength was observed between samples of $\mathbf{1} / \mathbf{2} / \mathrm{NN}(1.7 \mathrm{MPa})$ and $\mathbf{1} / \mathrm{NN}(0.9$ $\mathrm{MPa})$, indicating again contribution of amino groups of $\mathbf{1}$.

In summary, we have designed a heterobifunctional cross-linker by using Cys as a starting compound, and evaluated its curing ability in an anionic UV curing system of epoxy resins. Further application of this type of cross-linker is under investigation.

\section{References and Notes}

1. R. Auvergne, S. Caillol, G. David, B. Boutevin and J. -P. Pascault, Chem. Rev., 114 (2014) 1082.

2. (a) L. Shechter and J. Wynstra, Ind. Eng. Chem., 48 (1956) 86. (b) L. Shechter, J. Wynstra and R. P. Kurkjy, Int. Eng. Chem., 48 (1956) 94.

3. K. Arimitsu and R. Endo, Chem. Mater., 25 (2013) 4461.

4. A. Denise, S. V. Pizzo, G. Rozakis, and N. A. Porter, J. Am. Chem. Soc., 110 (1988) 244.

5. (a) K. Arimitsu, Y. Takemori, T. Gunji and Y. Abe, Polymer Preprint, 56 (2007) 4263. (b) K. Arimitsu, Y. Takemori, A. Nakajima, A. Oguri, M. Furutani, T. Gunji and Y. Abe, J. Polym. Sci. A: Polym. Chem., 53 (2015) 1174. (c) T. Ishii and K. Arimitsu, Polymer Preprint, 61 (2012) 1197.

6. L. A. Carpino and G. Y. Han, J. Am. Chem. Soc., 92 (1970) 5748.

7. PBG 2 was synthesized according to the literature [5b]. 8. JIS K5400 defined by Japanese Industrial Standards is a simple method to test the scratch hardness of coatings. The pencil (in the range of $6 \mathrm{~B}$ (softest) to $9 \mathrm{H}$ (hardest)) is moved scratching over the surface of the coating at a $45^{\circ}$ angle with a constant pressure. 